\title{
Prognostic impact of the expression of ALDH1 and SOX2 in urothelial cancer of the upper urinary tract
}

Hiroshi Kitamura, Toshihiko Torigoe, Yoshihiko Hirohashi, Hiroko Asanuma, Ryuta Inoue, Sachiyo Nishida, Toshiaki Tanaka, Fumimasa Fukuta, Naoya Masumori, Noriyuki Sato and Taiji Tsukamoto

Departments of Urology and Pathology, Sapporo Medical University School of Medicine, Sapporo, Japan

\begin{abstract}
Aldehyde dehydrogenase 1 (ALDH1) and sex determining region-Y-related high mobility group box 2 (SOX2) have been identified as putative cancer stem-like cell/tumor-initiating cell markers in various cancer tissues. The aim of this study was to elucidate the prognostic impact of these putative cancer stem-like cell/tumorinitiating cell markers in upper urinary tract urothelial cell carcinoma. Immunohistochemical staining for ALDH1 and SOX2 was carried out on archival specimens from 125 patients with upper urinary tract urothelial cell carcinoma who underwent radical nephroureterectomy. The prognostic value of ALDH1 and SOX2 expression and other clinicopathological features was evaluated. On univariate analysis, tumor grade, pathological T stage, pathological N stage, lymphovascular invasion, ALDH1 expression and SOX2 expression were associated with a poor prognosis. On multivariate analysis, the independent factors of prognosis were tumor grade $(P=0.014)$, pathological $\mathrm{N}$ stage $(P=0.005)$ and ALDH1 expression $(P=0.002)$. In subgroup analysis, those subgroups with no positive, one positive or two positive results in immunohistochemistry for ALDH1 and SOX2 expression had estimated 5 -year cancer-specific survival rates of $80 \%, 49 \%$ and $22 \%$, respectively $(P<0.001)$. Neither ALDH1 nor SOX2 expression correlated with intravesical recurrence after radical nephroureterectomy. These findings suggest that cancer stem-like cells/tumor-initiating cells are linked to more aggressive behavior of upper urinary tract urothelial cell carcinoma, supporting the current cancer stem cell hypothesis. Thus, therapeutic targeting of cancer stem-like cells/tumor-initiating cells in upper urinary tract urothelial cell carcinoma is a future possibility.

Modern Pathology (2013) 26, 117-124; doi:10.1038/modpathol.2012.139; published online 17 August 2012
\end{abstract}

Keywords: ALDH1; cancer stem cell; carcinoma; prognosis; SOX2; upper urinary tract; urothelial cell

Upper urinary tract urothelial cell carcinomas are uncommon and account for only $5-10 \%$ of urothelial carcinomas. ${ }^{1}$ Radical nephroureterectomy with excision of an ipsilateral bladder cuff is the standard therapy for patients with a normal contralateral kidney. ${ }^{2}$ Upper urinary tract urothelial cell carcinomas that invade the muscle wall usually have a very poor prognosis, even if radical nephroureterectomy is performed appropriately. ${ }^{1}$ The 5 -year specific survival is $<50 \%$ for pT2/ pT3 and $<10 \%$ for pT4. ${ }^{3,4}$ According to the most recent classifications,

Correspondence: Dr H Kitamura, MD, PhD, Department of Urology, Sapporo Medical University School of Medicine, South 1 West 16, Chuo-ku, Sapporo 060-8543, Japan.

E-mail: hkitamu@sapmed.ac.jp

Received 27 January 2012; revised 26 June 2012; accepted 26 June 2012; published online 17 August 2012 the primarily recognized prognostic factors are tumor stage and grade. ${ }^{1}$ Gender, age and the initial location of the tumor within the upper urinary tract are no longer accepted as prognostic factors. ${ }^{1}$ Lymphovascular invasion, ${ }^{5-7}$ tumor necrosis, ${ }^{8,9}$ tumor architecture ${ }^{10}$ and concomitant carcinoma in situ ${ }^{11,12}$ are associated with higher risks of recurrent disease and cancer-specific mortality. Molecular markers such as microsatellite instabilities, ${ }^{13}$ E-cadherin, hypoxia-inducible factor- $1 \alpha$ and a telomerase RNA component ${ }^{14}$ have been shown to be useful for prognosis, although none of the markers has been externally validated. ${ }^{1}$

Cancer stem-like cells/tumor-initiating cells are a small population of cancer cells that have the properties of tumor-initiating ability, self-renewal and differentiation. Cancer stem-like cells/tumor-initiating cells are more resistant to chemotherapy and radio- 
therapy than non-cancer stem-like cell/tumor-initiating cell populations via various mechanisms, ${ }^{15}$ suggesting that the existence of these cells is a prognostic factor in cancer patients. In this study, we investigated two cancer stem-like cell/tumor-initiating cell markers. Aldehyde dehydrogenase 1(ALDH1) is a cytosolic isoform of ALDH, and high levels of its activity are seen not only in hematopoietic stem/ progenitor cells but also in solid cancers (eg, breast, ${ }^{16,17}$ colorectal, ${ }^{18}$ pancreas, ${ }^{19}$ bladder $^{20}$ and prostate $^{21}$ cancers). Furthermore, expression of ALDH1 is a predictor of poor clinical outcome in the breast, ${ }^{16,22}$ lung, ${ }^{23}$ pancreatic ${ }^{19}$ and bladder ${ }^{20}$ cancers. Sex determining region-Y-related high mobility group box (SOX) 2 is a transcription factor that is involved in the maintenance of embryonic stem cell pluripotency and in multiple developmental processes. It is overexpressed in certain poorly differentiated subtypes of cancer (eg, lung, ${ }^{24,25}$ breast, ${ }^{26,27}$ and colorectal $^{28,29}$ cancers). SOX2 is not only a prognostic indicator in these cancers but also a candidate for cancer stem-like cell/tumor-initiating cell-targeting T-cell-based immunotherapy. ${ }^{30}$

The purpose of this study was therefore to evaluate the relationship between cancer stem-like cells/tumor-initiating cells and prognosis in upper urinary tract urothelial cell carcinoma by using the putative markers, ALDH1 and SOX2, with full clinicopathological data and follow-up. We also analyzed the association between cancer stem-like cell/tumor-initiating cell marker expression and recurrence, especially intravesical recurrence after radical nephroureterectomy.

\section{Materials and methods}

\section{Patients}

We reviewed the clinical pathology archives of 181 consecutive patients who underwent radical nephroureterectomy and were diagnosed as having upper urinary tract urothelial cell carcinomas at the Sapporo Medical University Hospital from June 1995 through May 2010. Patients with a previous history of bladder cancer and patients with concomitant bladder cancer were excluded. Finally, a total of 125 patients were enrolled in this study. Informed consent was obtained from the patients to use the surgical specimens remaining after pathological diagnosis for the investigational study, which was approved by the Institutional Review Board for Clinical Research at our university (No. 22-131). All hematoxylin- and eosin-stained slides were reviewed, and all of these specimens showed urothelial carcinoma. The median age at operation of the 89 male and 36 female patients was 69 years (range 32-88). Median follow-up was 69 months (range 6-192). All hematoxylin- and eosin-stained slides were reviewed, and clinical stage was assigned using the American Joint Committee on Cancer
Table 1 Characteristics of the 125 patients

\begin{tabular}{lc} 
Characteristics & \\
\hline Median age in years (range) & $69(32-88)$ \\
Median follow-up (months) & 69 \\
Sex & \\
Male & $89(71)$ \\
Female & $36(29)$ \\
Side & \\
Right & $54(43)$ \\
Left & $71(57)$ \\
& \\
Primary site (main) & \\
Renal pelvis & $75(60)$ \\
Ureter upper & $11(9)$ \\
$\quad$ Middle & $10(8)$ \\
Lower & $29(23)$ \\
& \\
Pathological stage & $16(13)$ \\
Stage 0a & $2(2)$ \\
Stage 0is & $17(14)$ \\
Stage I & $21(17)$ \\
Stage II & $50(40)$ \\
Stage III & $19(15)$ \\
Stage IV & \\
Chemotherapy & \\
Neoadjuvant & $6(8)$ \\
Adjuvant &
\end{tabular}

Values are $N(\%)$ except where mentioned otherwise.

TNM Staging System for Renal Pelvis and Ureter Cancer (7th edition, 2010). ${ }^{31}$ The patients' characteristics are shown in Table 1.

\section{Immunohistochemistry and Scoring}

Sections $(4 \mu \mathrm{m})$ of the formalin-fixed, paraffinembedded tumor specimens were immunostained after heat-induced epitope retrieval in citrate buffer (pH 6.0) using an autoclave with a monoclonal antibody against ALDH1 (dilution 1:1000; BD Transduction Laboratories, San Diego, CA, USA) and a polyclonal antibody against SOX2 (dilution 1:100; Invitrogen, Camarillo, CA, USA). Subsequent incubations with a secondary biotinylated antibody, avidin-conjugated peroxidase complex and chromogen were done on a Ventana NexES (Ventana Medical Systems, Tucson, AZ, USA). The slides were then counterstained with hematoxylin, rinsed, dehydrated through graded alcohols into nonaqueous solution, and cover-slipped with mounting media. Negative controls had the primary antibody replaced by buffer. All specimens were reviewed independently using light microscopy in at least five areas at $\times 400$ magnification by investigators who were blinded to clinicopathological data (TT and YH). For ALDH1, tumors presenting at least one ALDH1-positive cancer cell were considered to be ALDH1 positive. ${ }^{16,32}$ For SOX2, nuclear staining 
was considered positive. ${ }^{33}$ We previously reported that the SOX2-positive rates in lung cancer were $15 \%, 45 \%$ and $40 \%$ in $<1 \%, 1-10 \%$ and $>10 \%$ of tumors, respectively. ${ }^{33}$ On the basis of these results, we used a 10\% cutoff point for both negative and positive specimens. Breast and lung cancer tissues were used as positive controls for ALDH1 and SOX2, respectively.

\section{Statistical Analysis}

We tested the relationships between ALDH1/SOX2 and the other clinicopathological parameters, ie, the pathological $\mathrm{T}$ stage, pathological $\mathrm{N}$ stage, tumor grade and lymphovascular invasion by $\chi^{2}$ tests. Cancer-specific survival, overall survival, recurrence-free survival and intravesical recurrence-free survival were assessed by the Kaplan-Meier method, and differences between two groups were compared using the log-rank test. For the test of intravesical recurrence-free survival, 16 patients with stage IV disease were excluded. The subgroups with two positive, one positive and no positive immunohistochemistry results for ALDH1 and SOX2 expression were analyzed. Univariate and multivariate regression analyses according to the Cox proportional hazards regression model, with cancer-specific survival as the dependent variable, were used to evaluate the expression of ALDH1 and SOX2 as potential independent prognostic factors. A value of $P<0.05$ was considered to indicate statistical significance. The calculations were performed using JMP ${ }^{\mathrm{TM}}$ software.

\section{Results}

\section{Expression and Localization of ALDH1 and SOX2}

Scattered ALDH1-positive cells were observed in $34(27 \%)$ of the 125 cases (Figure 1b). The ALDH1
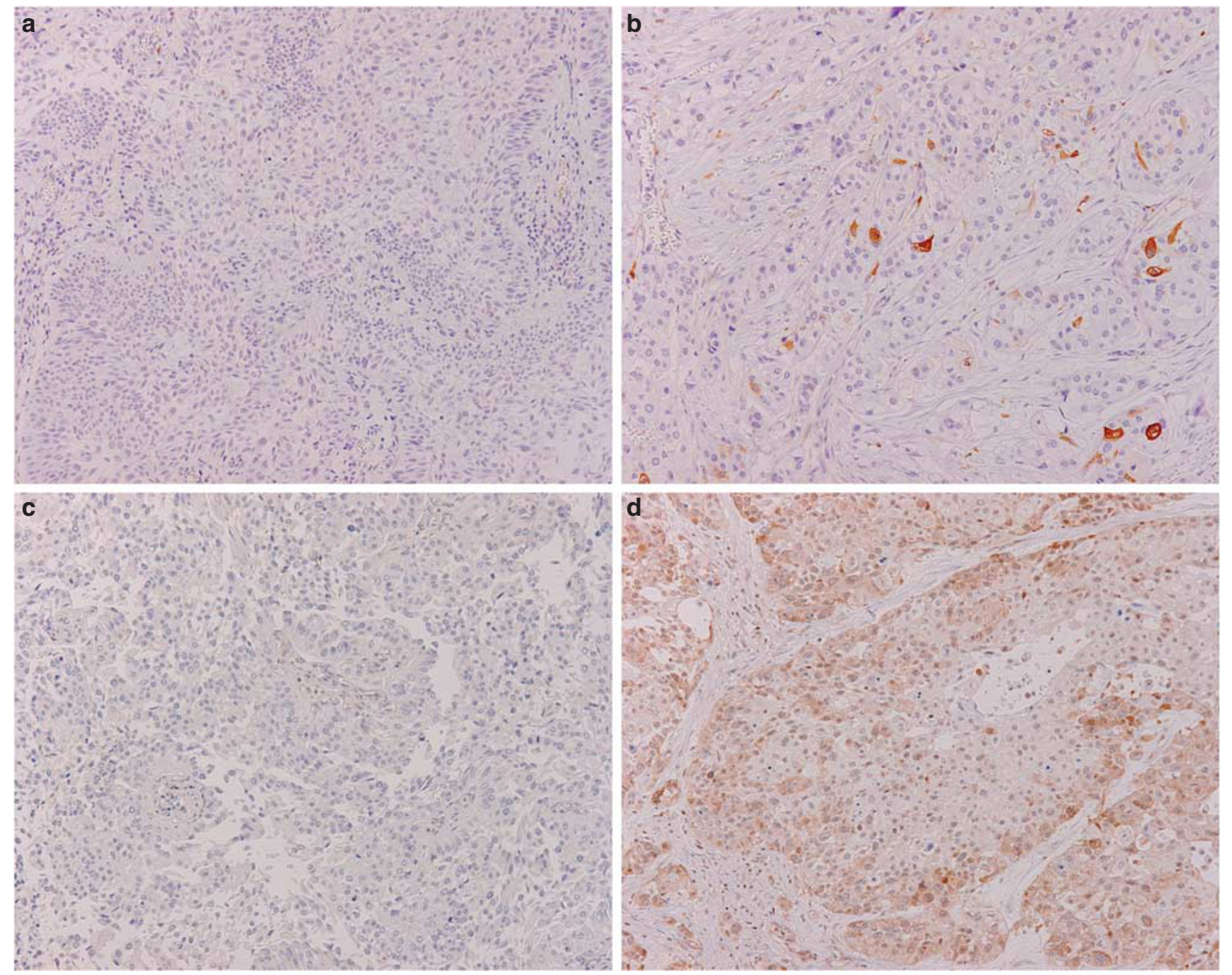

Figure 1 Representative immunohistochemical staining of aldehyde dehydrogenase 1 (ALDH1) and sex determining region-Y-related high mobility group box 2 (SOX2). (a) Negative ALDH1 expression in tumor cells, (b) positive ALDH1 expression in tumor cells, (c) negative SOX2 expression in tumor cells and (d) positive SOX2 expression in tumor cells. 
Table 2 Frequency of positive expression of cancer stem-like cell/tumor-initiating cell (CSC/TIC) markers

\begin{tabular}{ll}
\hline CSC/TIC markers & $\mathrm{n}(\%)$ \\
\hline ALDH1 $^{\text {pos } S O X 2 \text { pos }}$ & $11(9)$ \\
ALDH1 $^{\text {pos } S O X 2} 2^{\text {neg }}$ & $23(18)$ \\
ALDH1 $^{\text {neg SOX2 }} 2^{\text {pos }}$ & $13(11)$ \\
ALDH1 $^{\text {neg }}$ SOX2 &
\end{tabular}

expression was strongly present in the cytoplasm. SOX2 expression was mainly positive in cells located in the peripheral regions of tumor nests, and diffuse cytoplasmic and nuclear staining was observed in 24 cases (19\%) (Figure 1d). We examined the mRNA expression of ALDH1 and SOX2 by RT-PCR (Supplementary Information) and compared it with immunohistochemical expression of these genes in the same nine tissues. The concordance rates between the two methods were $78 \%$ for ALDH1 and $89 \%$ for SOX2 (Supplementary Figure S1). The rates of SOX2-positive cells were $<1 \%, 1-10 \%$ and $>10 \%$ in $19 \% \quad(n=24), 62 \%$ $(n=77)$ and $19 \%(n=24)$ of the cases, respectively. The percentages of ALDH1- and SOX2-positive cancer cells were counted and subjected to statistical analysis. The frequencies of the expression of cancer stem-like cell/tumor-initiating cell markers are shown in Table 2. In cases that were both ALDH1- and SOX2-positive, the tumor cells were ALDH1- or SOX2-positive or double-positive. Immunohistochemical staining of ALDH1 and SOX2 in a representative double-positive case is shown in Supplementary Figure S2.

\section{Associations Between Expression of ALDH1 and SOX2 and Clinicopathological Variables (Table 3)}

ALDH1 expression was linked to lymph node metastasis $(P=0.047)$ and lymphovascular invasion $(P=0.038)$. SOX2 expression was significantly associated with more advanced pathological $\mathrm{T}$ stage $(P=0.032)$, more advanced pathological $\mathrm{N}$ stage $(P=0.019)$, and as well as with a trend toward to higher tumor grade $(P=0.017)$.

\section{Association of ALDH1 and/or SOX2 with Survival and Recurrence}

The 5-year cancer-specific survival rates of patients with ALDH1-negative and -positive tumors were $74 \%$ and $36 \%$, respectively (Figure $2 \mathrm{a}$ ). The 5 -year cancer-specific survival rates of patients with SOX2negative and -positive tumors were 72 and $46 \%$, respectively (Figure 2b). There were significant differences in cancer-specific survival between patients with ALDH1-negative tumors and those with ALDH1-positive tumors $(P<0.001$, Figure 2a), and between patients with SOX2-negative tumors
Table 3 ALDH1/SOX2 expression and pathological factors in patients with upper urinary tract urothelial cell carcinoma

\begin{tabular}{|c|c|c|c|c|c|c|}
\hline \multirow{2}{*}{ Variable } & \multicolumn{3}{|c|}{$A L D H 1$} & \multicolumn{3}{|c|}{ SOX2 } \\
\hline & $\begin{array}{c}\text { Positive } \\
(\%)\end{array}$ & $\begin{array}{c}\text { Negative } \\
(\%)\end{array}$ & $\begin{array}{c}\mathrm{P}- \\
\text { value }\end{array}$ & $\begin{array}{c}\text { Positive } \\
(\%)\end{array}$ & $\begin{array}{c}\text { Negative } \\
(\%)\end{array}$ & $\begin{array}{c}\mathrm{P}- \\
\text { value }\end{array}$ \\
\hline \multicolumn{7}{|c|}{ Pathological T stage } \\
\hline $\mathrm{pTa}$ & $2(6)$ & $0(0)$ & 0.184 & $1(4)$ & $1(1)$ & 0.032 \\
\hline pTis & $3(9)$ & $13(14)$ & & $1(4)$ & $15(15)$ & \\
\hline pT1 & $3(9)$ & $15(16)$ & & $4(17)$ & $14(14)$ & \\
\hline pT2 & $6(18)$ & 17 (19) & & $1(4)$ & $22(22)$ & \\
\hline pT3 & $18(52)$ & $43(48)$ & & $14(58)$ & $47(46)$ & \\
\hline pT4 & $2(6)$ & $3(3)$ & & $3(13)$ & $2(2)$ & \\
\hline \multicolumn{7}{|c|}{ Pathological N stage } \\
\hline pNo & $27(79)$ & $85(94)$ & 0.047 & $18(75)$ & $94(93)$ & 0.019 \\
\hline pN1 & $4(12)$ & $2(2)$ & & $2(8)$ & $4(4)$ & \\
\hline $\mathrm{pN} 2$ & $3(9)$ & $4(4)$ & & $4(17)$ & $3(3)$ & \\
\hline \multicolumn{7}{|l|}{ Grade } \\
\hline G1 & $0(0)$ & $3(3)$ & 0.083 & $1(4)$ & $2(2)$ & 0.017 \\
\hline G2 & $10(29)$ & $43(47)$ & & $4(17)$ & $49(48)$ & \\
\hline G3 & $24(71)$ & $45(50)$ & & $19(79)$ & $50(50)$ & \\
\hline \multicolumn{7}{|c|}{ Lymphovascular invasion } \\
\hline Negative & $17(50)$ & $64(70)$ & 0.038 & $13(54)$ & $68(67)$ & 0.242 \\
\hline Positive & $17(50)$ & $27(30)$ & & $11(46)$ & $33(33)$ & \\
\hline
\end{tabular}

and those with SOX2-positive tumors $(P=0.003$, Figure 2b). Thus, both ALDH1 and SOX2 expression correlated with cancer-specific survival. The subgroups with no positive, one positive or two positive immunohistochemistry results for ALDH1 and SOX2 expression had estimated 5-year cancerspecific survival rates of $80 \%, 49 \%$, and $22 \%$, respectively ( $P<0.001$, Figure 2c).

Kaplan-Meier plots and log-rank tests showed that the upper urinary tract urothelial cell carcinoma patients with ALDH1-positive tumor cells had significantly shorter overall survival, than those whose tumors were ALDH1-negative $(P<0.001)$. The 5-year overall survival rates of patients with ALDH1-negative and -positive tumors were $63 \%$ and $31 \%$, respectively. The 5 -year overall survival rates of patients with SOX2-negative and -positive tumors were $62 \%$ and $36 \%$, respectively. There was a significant difference in overall survival between the two groups $(P=0.019)$.

The 5-year recurrence-free survival rates of patients with ALDH1-negative and -positive tumors were $43 \%$ and $24 \%$, respectively (Figure 3a). There was a significant difference in recurrence-free survival between the two groups $(P=0.024)$. In contrast, no difference was observed in recurrencefree survival between patients with SOX2-negative tumors and those with SOX2-positive tumors (Figure 3b). During the follow-up, 34 (32\%) of 106 patients undergoing radical nephroureterectomy for stage $\leq$ III disease had intravesical recurrence. Of the 34 patients, $13(38 \%)$ had systemic recurrence and $8(24 \%)$ died of UC. Neither ALDH1 nor SOX2 expression correlated with intravesical recurrencefree survival (Figures 3c and d). 
a

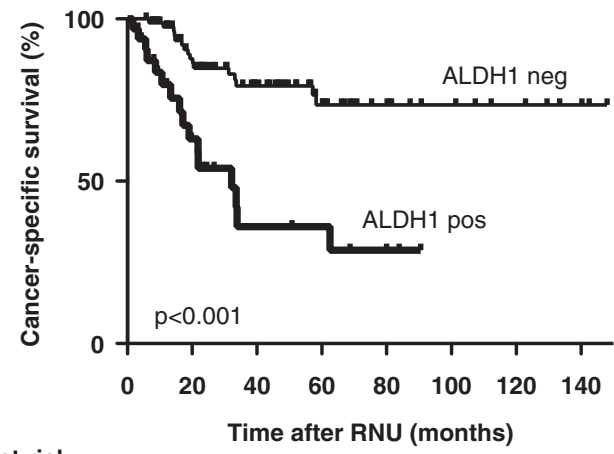

Number at risk

$\begin{array}{lllllllll}\text { ALDH1 neg } & 86 & 62 & 41 & 25 & 15 & 10 & 7 & 4\end{array}$

ALDH1 pos

$\begin{array}{llllllll}33 & 15 & 7 & 6 & 3 & 1 & 1 & 1\end{array}$

b

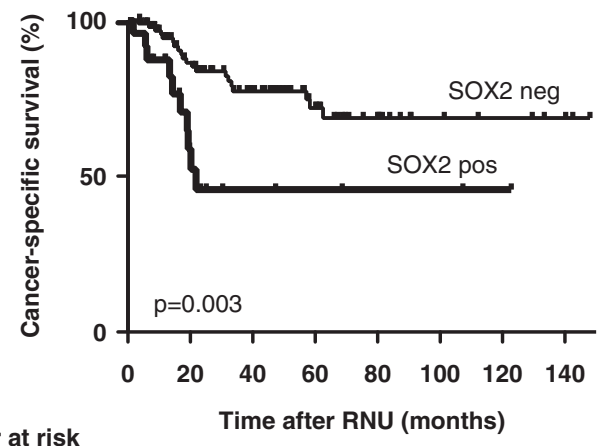

Number at risk

$\begin{array}{lllllllll}\text { soX2 neg } & 94 & 66 & 44 & 27 & 15 & 8 & 6 & 4\end{array}$

sox2 pos

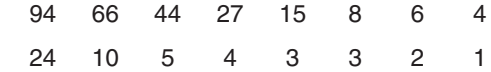

C

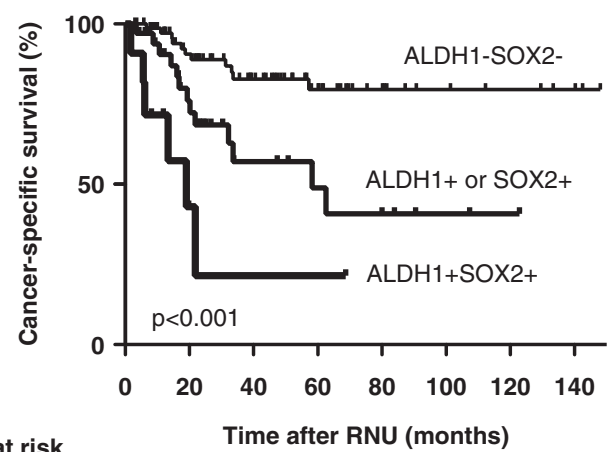

Number at risk

$\begin{array}{lllllllll}\text { ALDH1-SOX2- } & 74 & 55 & 38 & 23 & 13 & 8 & 7 & 4\end{array}$

$\begin{array}{lllllllll}\text { ALDH1+ or SOX2+ } & 35 & 21 & 10 & 7 & 5 & 3 & 2 & 1\end{array}$

$\begin{array}{lllllllll}\mathrm{ALDH}+\mathrm{SOX} 2+ & 11 & 3 & 2 & 2 & 1 & 1 & 1 & 1\end{array}$

Figure 2 Kaplan-Meier curves for cancer-specific survival rates according to (a) aldehyde dehydrogenase 1 (ALDH1) expression status, (b) sex determining region-Y-related high mobility group box 2 (SOX2) expression status and (c) combined expression status of ALDH1 and SOX2.

In univariate analysis, the pathological $\mathrm{T}$ stage, pathological $\mathrm{N}$ stage, tumor grade, lymphovascular invasion, ALDH1 and SOX2 were associated with a poor prognosis (Table 4). In multivariate analysis, the independent factors of prognosis were the pathological $\mathrm{N}$ stage $(P=0.005)$, tumor grade $(P=0.014)$ and ALDH1 expression $(P=0.002)$ (Table 4$)$.

\section{Discussion}

To the best of our knowledge, this is the first study in which the relationships between expression of putative cancer stem-like cell/tumor-initiating cell markers and the most clinically relevant features of upper urinary tract urothelial cell carcinoma were evaluated. We demonstrated that expression of both ALDH1 and SOX2 correlated with cancer-specific survival. In contrast, expression of these markers was not associated with intravesical recurrence-free survival. These findings suggested that cancer stemlike cells/tumor-initiating cells were linked to more aggressive behavior of upper urinary tract urothelial cell carcinoma.

We demonstrated that ALDH1 was not only an independent factor for prognosis but also associated with recurrence-free survival, although there was no relationship between ALDH1 expression and intravesical recurrence-free survival. Brandt et $a l^{34}$ found that ALDH1 was significantly upregulated in urothelial cancer stem-like cells compared with non-cancer stem-like cells, indicating a potential mode of chemoresistance in urothelial cancer stemlike cells. $\mathrm{Su}$ et $a l^{20}$ reported that high ALDH1 expression was associated with poor prognosis for patients with bladder urothelial carcinoma and was an independent predictor for cancer-specific survival. Various studies have reported that immunohistochemically identified tumor ALDH1 expression is associated with a poor prognosis in breast, ${ }^{16,22}$ lung, ${ }^{23}$ and pancreatic ${ }^{19}$ cancer patients. Conversely, ALDH1 has a favorable function in ovarian carcinoma and high expression of ALDH1 is a favorable prognostic factor in patients with ovarian cancer. ${ }^{35}$ In a large study including 1420 patients with colorectal cancer of all stages, no significant correlation could be found between ALDH expression and survival, ${ }^{36}$ whereas the ALDH1 expression pattern had a significant impact upon survival for G2 T3N0M0 colorectal cancer in another study. ${ }^{37}$ Our findings suggest that upper urinary tract urothelial cell carcinoma contains ALDH1positive cancer stem-like cells/tumor-initiating cells like bladder cancer, and that these cells are associated with survival or life-threatening disease, as $62 \%$ of the patients with intravesical recurrence were alive without any other recurrence.

Although the roles of SOX2 in cancer cells are still elusive, SOX2 is considered one of the candidate cancer stem-like cell/tumor-initiating cell antigens. ${ }^{15}$ We previously demonstrated that SOX2overexpressing lung adenocarcinoma cell lines showed higher rates of side population cells and higher tumorigenecity and that SOX2 mRNA knockdown of side population cells by gene-specific siRNA completely abrogated tumorigenecity in vivo. ${ }^{33}$ In this study, we found that SOX2 was associated with cancer-specific survival in patients with upper urinary tract urothelial cell carcinoma. Although there has been no report showing the 
a

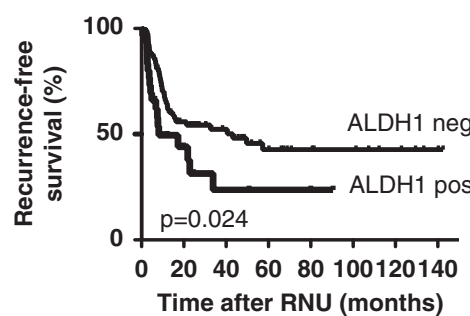

Number at risk

$\begin{array}{lllllllll}\text { ALDH1 neg } 80 & 36 & 26 & 16 & 11 & 9 & 6 & 3\end{array}$

$\begin{array}{lllllllll}\text { ALDH1 pos } & 30 & 8 & 4 & 3 & 2 & 1 & 1 & 1\end{array}$

C

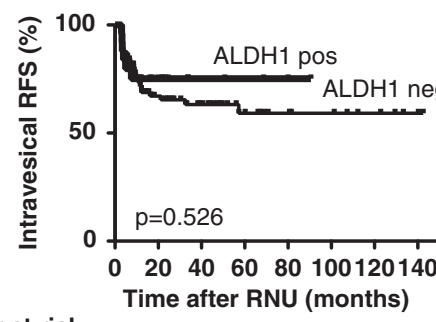

Number at risk

$\begin{array}{lllllllll}\text { ALDH1 neg } & 81 & 39 & 27 & 16 & 11 & 9 & 6 & 3\end{array}$

$\begin{array}{lllllllll}\text { ALDH1 pos } & 25 & 11 & 5 & 4 & 2 & 1 & 1 & 1\end{array}$ b

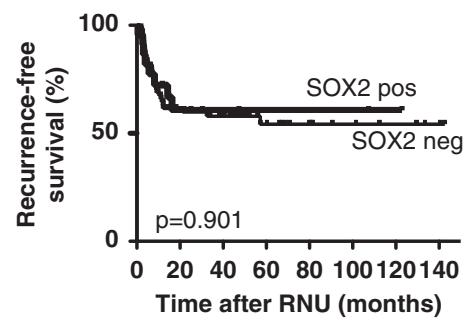

Number at risk

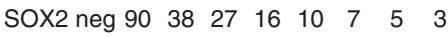

$\begin{array}{llllllll}\text { soX2 pos } 23 & 7 & 4 & 3 & 3 & 3 & 2 & 1\end{array}$

d

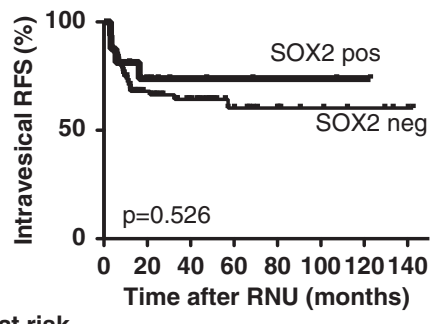

Number at risk

$\begin{array}{lllllllll}\text { SOX2 neg } & 90 & 42 & 27 & 16 & 10 & 7 & 5 & 3\end{array}$

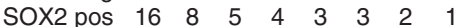

Figure 3 Kaplan-Meier curves for recurrence-free survival rates according to (a) aldehyde dehydrogenase 1 (ALDH1) expression status and (b) sex determining region-Y-related high mobility group box 2 (SOX2) expression status, and for intravesical recurrence-free survival rates according to (c) ALDH1 expression status and (d) SOX2 expression status.

Table 4 Prognostic factors for cancer-specific survival in univariate and multivariate analyses

\begin{tabular}{|c|c|c|c|c|}
\hline \multirow{2}{*}{ Factor } & \multicolumn{2}{|c|}{ Univariate analysis } & \multicolumn{2}{|c|}{ Multivariate analysis } \\
\hline & $H R(95 \% C I)$ & $\mathrm{P}$-value & HR $(95 \% C I)$ & $\mathrm{P}$-value \\
\hline Pathological T stage & $2.76(1.69-4.89)$ & $<0.001$ & $1.68(0.94-3.16)$ & 0.082 \\
\hline Pathological N stage & $2.75(1.75-4.09)$ & $<0.001$ & $2.18(1.29-3.60)$ & 0.005 \\
\hline Grade & $6.02(2.53-17.7)$ & $<0.001$ & $3.36(1.26-10.6)$ & 0.014 \\
\hline Lymphovascular invasion & $2.18(1.52-3.25)$ & $<0.001$ & $1.22(0.76-1.96)$ & 0.433 \\
\hline ALDH1 & $1.97(1.38-2.81)$ & $<0.001$ & $1.89(1.28-2.79)$ & 0.002 \\
\hline SOX2 & $1.78(1.21-2.55)$ & 0.005 & $1.30(0.83-1.98)$ & 0.256 \\
\hline
\end{tabular}

relationship between SOX expression and prognosis in UC, Ben-Porath et al ${ }^{38}$ reported enriched patterns of gene sets associated with embryotic stem cell identity, including SOX2, in the expression profiles of bladder carcinoma. They demonstrated that highgrade tumors showed an embryotic stem-like gene set enrichment pattern, and concluded that an embryotic stem-like signature was present in poorly differentiated cancers from distinct cells of origin. In the present study, SOX2 expression was significantly associated with tumor grade, pathological T stage and pathological $\mathrm{N}$ stage. This may explain why SOX2 expression was an independent factor for survival by univariate analysis but not by multivariate analysis. Several studies have reported that SOX2 is upregulated in various cancers other than urothelial carcinoma, including lung adenocarcinoma, ${ }^{25}$ gastric carcinoma, ${ }^{39}$ breast carcinoma, ${ }^{27}$ head and neck squamous cell carcinomas, ${ }^{40,41}$ hepatocellular carcinoma $^{42}$ and rectal cancer. ${ }^{28}$ Meanwhile, another study on gastric cancer reported that SOX2 expression was related to better prognosis. ${ }^{43}$ SOX2 expression is associated with a better outcome in squamous cell lung cancer. ${ }^{44}$

On the basis of the abilities for tumor initiation, self-renewal and differentiation, various putative cancer stem-like cell/tumor-initiating cell markers have been used. ${ }^{45}$ As these markers (such as side population, CD44 + /CD24-, CD133 + , ALDH1, SOX2, Oct3/4, etc.) show distinct properties of cancer stem cells, tumor tissues can show heterogeneity when multiple markers are examined. These vary depending on the cancer, and not all tumor cells identified by certain markers are cancer stemlike cells/tumor-initiating cells. ${ }^{46}$ In this study, $18 \%, 10 \%$ and $9 \%$ of the upper urinary tract urothelial cell carcinoma cases had ALDH1 ${ }^{\text {pos }} S O X 2^{\text {neg, }}$ ALDH1 ${ }^{\text {neg }}{ } \mathrm{OX} 2^{\text {pos }}$ and ALDH1 ${ }^{\text {pos }} \mathrm{SOX} 2^{\text {pos }}$ tumor 
cells, respectively (Table 2). Furthermore, the number of upper urinary tract urothelial cell carcinoma cells immunohistochemically stained for both ALDH1 and SOX2, which are considered to have more characteristics of cancer stem-like cell/tumorinitiating cell, was limited in these cases (Supplementary Figure S2). These results are compatible with reported cancer stem-like cell/tumor-initiating cell frequencies, which ranged from 1 in 2500 to 1 in 36000 in various cancers. ${ }^{47}$

There are several limitations to our study. First are the limitations inherent to any retrospective study. Second, radical nephroureterectomy was performed by various surgeons over a long time period. Third, immunohistochemistry has inherent limitations such as reproducibility and reliability. Finally, the roles of ALDH1 and SOX2 in upper urinary tract urothelial cell carcinoma require further investigation.

In summary, the current results demonstrate a direct link between the expression of cancer stemlike cell/tumor-initiating cell markers and patient survival in upper urinary tract urothelial cell carcinoma. Our data support the current cancer stem cell hypothesis for upper urinary tract urothelial cell carcinoma, which suggests that therapeutic targeting of cancer stem-like cells/tumor-initiating cells in upper urinary tract urothelial cell carcinoma is a future possibility.

\section{Disclosure/conflict of interest}

The authors declare no conflict of interest.

\section{References}

1 Roupret M, Zigeuner R, Palou J, et al. European guidelines for the diagnosis and management of upper urinary tract urothelial cell carcinomas: 2011 update. Eur Urol 2011;59:584-594.

2 Raman JD, Scherr DS. Management of patients with upper urinary tract transitional cell carcinoma. Nat Clin Pract Urol 2007;4:432-443.

3 Abouassaly R, Alibhai SM, Shah N, et al. Troubling outcomes from population-level analysis of surgery for upper tract urothelial carcinoma. Urology 2010;76: 895-901.

4 Jeldres C, Sun M, Isbarn H, et al. A population-based assessment of perioperative mortality after nephroureterectomy for upper-tract urothelial carcinoma. Urology 2010;75:315-320.

5 Kikuchi E, Margulis V, Karakiewicz PI, et al. Lymphovascular invasion predicts clinical outcomes in patients with node-negative upper tract urothelial carcinoma. J Clin Oncol 2009;27:612-618.

$6 \mathrm{Kim}$ DS, Lee YH, Cho KS, et al. Lymphovascular invasion and pT stage are prognostic factors in patients treated with radical nephroureterectomy for localized upper urinary tract transitional cell carcinoma. Urology 2010;75:328-332.
7 Novara G, Matsumoto K, Kassouf W, et al. Prognostic role of lymphovascular invasion in patients with urothelial carcinoma of the upper urinary tract: an international validation study. Eur Urol 2010;57:1064-1071.

8 Zigeuner R, Shariat SF, Margulis V, et al. Tumour necrosis is an indicator of aggressive biology in patients with urothelial carcinoma of the upper urinary tract. Eur Urol 2010;57:575-581.

9 Seitz C, Gupta A, Shariat SF, et al. Association of tumor necrosis with pathological features and clinical outcome in 754 patients undergoing radical nephroureterectomy for upper tract urothelial carcinoma: an international validation study. J Urol 2010;184: 1895-1900.

10 Remzi M, Haitel A, Margulis V, et al. Tumour architecture is an independent predictor of outcomes after nephroureterectomy: a multi-institutional analysis of 1363 patients. BJU Int 2009;103:307-311.

11 Pieras E, Frontera G, Ruiz X, et al. Concomitant carcinoma in situ and tumour size are prognostic factors for bladder recurrence after nephroureterectomy for upper tract transitional cell carcinoma. BJU Int 2010;106:1319-1323.

12 Wheat JC, Weizer AZ, Wolf JS Jr, et al. Concomitant carcinoma in situ is a feature of aggressive disease in patients with organ confined urothelial carcinoma following radical nephroureterectomy. Urol Oncol 2012;30:252-258.

13 Roupret M, Fromont G, Azzouzi AR, et al. Microsatellite instability as predictor of survival in patients with invasive upper urinary tract transitional cell carcinoma. Urology 2005;65:1233-1237.

14 Eltz S, Comperat E, Cussenot O, et al. Molecular and histological markers in urothelial carcinomas of the upper urinary tract. BJU Int 2008;102:532-535.

15 Hirohashi $\mathrm{Y}$, Torigoe $\mathrm{T}$, Inoda $\mathrm{S}$, et al. Immune response against tumor antigens expressed on human cancer stem-like cells/tumor-initiating cells. Immunotherapy 2010;2:201-211.

16 Charafe-Jauffret E, Ginestier C, Iovino F, et al. Aldehyde dehydrogenase 1-positive cancer stem cells mediate metastasis and poor clinical outcome in inflammatory breast cancer. Clin Cancer Res 2010;16:45-55.

17 Ohi Y, Umekita Y, Yoshioka T, et al. Aldehyde dehydrogenase 1 expression predicts poor prognosis in triple-negative breast cancer. Histopathology 2011; 59:776-780.

18 Lugli A, Iezzi G, Hostettler I, et al. Prognostic impact of the expression of putative cancer stem cell markers CD133, CD166, CD44s, EpCAM, and ALDH1 in colorectal cancer. Br J Cancer 2010;103:382-390.

19 Kahlert C, Bergmann F, Beck J, et al. Low expression of aldehyde dehydrogenase 1A1 (ALDH1A1) is a prognostic marker for poor survival in pancreatic cancer. BMC Cancer 2011;11:275.

$20 \mathrm{Su}$ Y, Qiu Q, Zhang X, et al. Aldehyde dehydrogenase 1 A1-positive cell population is enriched in tumorinitiating cells and associated with progression of bladder cancer. Cancer Epidemiol Biomarkers Prev 2010;19:327-337.

21 Jeter CR, Liu B, Liu X, et al. NANOG promotes cancer stem cell characteristics and prostate cancer resistance to androgen deprivation. Oncogene 2011;30:3833-3845.

22 Ginestier C, Hur MH, Charafe-Jauffret E, et al. ALDH1 is a marker of normal and malignant human mammary stem cells and a predictor of poor clinical outcome. Cell Stem Cell 2007;1:555-567. 
23 Jiang F, Qiu Q, Khanna A, et al. Aldehyde dehydrogenase 1 is a tumor stem cell-associated marker in lung cancer. Mol Cancer Res 2009;7:330-338.

$24 \mathrm{Lu} \mathrm{Y,} \mathrm{Futtner} \mathrm{C,} \mathrm{Rock} \mathrm{JR,} \mathrm{et} \mathrm{al.} \mathrm{Evidence} \mathrm{that} \mathrm{SOX2}$ overexpression is oncogenic in the lung. PloS One 2010;5:e11022.

25 Sholl LM, Barletta JA, Yeap BY, et al. Sox2 protein expression is an independent poor prognostic indicator in stage I lung adenocarcinoma. Am J Surg Pathol 2010;34:1193-1198.

26 Rodriguez-Pinilla SM, Sarrio D, Moreno-Bueno G, et al. Sox2: a possible driver of the basal-like phenotype in sporadic breast cancer. Mod Pathol 2007;20: 474-481.

27 Lengerke C, Fehm T, Kurth R, et al. Expression of the embryonic stem cell marker SOX2 in early-stage breast carcinoma. BMC Cancer 2011;11:42.

28 Saigusa S, Tanaka K, Toiyama Y, et al. Correlation of CD133, OCT4, and SOX2 in rectal cancer and their association with distant recurrence after chemoradiotherapy. Ann Surg Oncol 2009;16:3488-3498.

29 Inoda S, Hirohashi Y, Torigoe T, et al. Cytotoxic T lymphocytes efficiently recognize human colon cancer stem-like cells. Am J Pathol 2011;178:1805-1813.

30 Schmitz M, Temme A, Senner V, et al. Identification of SOX2 as a novel glioma-associated antigen and potential target for T cell-based immunotherapy. Br J Cancer 2007;96:1293-1301.

31 Renal pelvis and ureter. In: Edge SB, Byrd DR, Compton CC, et al., eds.: AJCC Cancer Staging Manual. 7th edn. Springer: New York, NY, 2010, pp 493.

32 Zhang Y, Toy KA, Kleer CG. Metaplastic breast carcinomas are enriched in markers of tumor-initiating cells and epithelial to mesenchymal transition. Mod Pathol 2012;25:178-184.

33 Nakatsugawa M, Takahashi A, Hirohashi Y, et al. SOX2 is overexpressed in stem-like cells of human lung adenocarcinoma and augments the tumorigenicity. Lab Invest 2011;91:1796-1804.

34 Brandt WD, Matsui W, Rosenberg JE, et al. Urothelial carcinoma: stem cells on the edge. Cancer Met Rev 2009;28:291-304.

35 Chang B, Liu G, Xue F, et al. ALDH1 expression correlates with favorable prognosis in ovarian cancers. Mod Pathol 2009;22:817-823.
36 Hessman CJ, Bubbers EJ, Billingsley KG, et al. Loss of expression of the cancer stem cell marker aldehyde dehydrogenase 1 correlates with advanced-stage colorectal cancer. Am J Surgery 2012;203:649-653.

37 Vogler T, Kriegl L, Horst D, et al. The expression pattern of aldehyde dehydrogenase 1 (ALDH1) is an independent prognostic marker for low survival in colorectal tumors. Exp Mol Pathol 2012;92: 111-117.

38 Ben-Porath I, Thomson MW, Carey VJ, et al. An embryonic stem cell-like gene expression signature in poorly differentiated aggressive human tumors. Nat Genet 2008;40:499-507.

39 Matsuoka J, Yashiro M, Sakurai K, et al. Role of the stemness factors Sox2, Oct3/4, and Nanog in gastric carcinoma. J Surg Res 2012;174:130-135.

40 Wang X, Liang Y, Chen Q, et al. Prognostic significance of SOX2 expression in nasopharyngeal carcinoma. Cancer Invest 2012;30:79-85.

41 Du L, Yang Y, Xiao X, et al. Sox2 nuclear expression is closely associated with poor prognosis in patients with histologically node-negative oral tongue squamous cell carcinoma. Oral Oncol 2011;47:709-713.

42 Huang P, Qiu J, Li B, et al. Role of Sox2 and Oct4 in predicting survival of hepatocellular carcinoma patients after hepatectomy. Clin Biochem 2011;44: 582-589.

43 Zhang $\mathrm{X}$, Yu H, Yang $\mathrm{Y}$, et al. SOX2 in gastric carcinoma, but not Hath1, is related to patients' clinicopathological features and prognosis. J Gastrointest Surg 2010;14:1220-1226.

44 Wilbertz T, Wagner P, Petersen $\mathrm{K}$, et al. SOX2 gene amplification and protein overexpression are associated with better outcome in squamous cell lung cancer. Mod Pathol 2011;24:944-953.

45 Alison MR, Lim SM, Nicholson LJ. Cancer stem cells: problems for therapy? J Pathol 2011;223: 147-161

46 Marcato P, Dean CA, Giacomantonio CA, et al. Aldehyde dehydrogenase: its role as a cancer stem cell marker comes down to the specific isoform. Cell Cycle 2011;10:1378-1384.

47 Ishizawa K, Rasheed ZA, Karisch R, et al. Tumorinitiating cells are rare in many human tumors. Cell Stem Cell 2010;7:279-282.

Supplementary Information accompanies the paper on Modern Pathology website (http://www.nature.com/ modpathol) 